ISSN 0258-7122

Bangladesh J. Agril. Res. 38(2): 247-255, June 2013

\title{
EFFECT OF STORAGE PERIODS ON POSTHARVEST QUALITY OF PUMPKIN
}

\author{
M. A. RAHMAN ${ }^{1}$, M. MIARUDDIN ${ }^{2}$, M. H. H. $\operatorname{KHAN}^{1}$ \\ M. A. T. MASUD ${ }^{3}$ AND M.M. BEGUM ${ }^{4}$
}

\begin{abstract}
The fully matured pumpkins (Cucurbita moschata Poir) of BARI Pumpkin-1 and BARI Pumpkin-2 were harvested from the experimental field of Horticulture Research Centre, BARI, Gazipur, Bangladesh. They were then stored under ambient room conditions $\left(27-31{ }^{\circ} \mathrm{C}\right.$ and $\left.75-90 \% \mathrm{RH}\right)$ for various periods ranged from 15 days to 120 days. The effect of different storage periods was assessed by evaluating their impact on changes in quality attributes of pumpkins. Results indicated that a slow but steady weight loss occurred in pumpkin with maximum loss of 18 and $21 \%$ after 120 days of storage in BARI Pumpkin-1 and BARI Pumpkin-2, respectively. $\beta$-carotene and ascorbic acid contents were decreased throughout the whole storage time, however, they were drastically reduced during first 30 days of storage. Total soluble solids content increased until 45 days of storage followed by a decrease with progress in time. Titratable acidity was slowly decreased and simultaneously $\mathrm{pH}$ value was increased throughout the storage period. The results indicated that storage conditions need to be managed carefully to slow down any changes in fresh pumpkin.
\end{abstract}

Keywords: Pumpkin, postharvest storage, ambient conditions, nutritional degradation.

\section{Introduction}

Pumpkin is one of the most important vegetable crops grown extensively throughout the tropical and subtropical countries. Due to its high nutritional content and lucrative market price, pumpkin may be considered as a high value crop. In Bangladesh, both immature and mature fruits are used as a vital ingredient for several culinary preparations.

Pumpkins are rich in carbohydrate and minerals and cheaper source of vitamins, especially carotenoid pigments (Bose and Som, 1986), which have a major role in nutrition in the form of pro-vitamin A, antioxidants, when used at ripening stage (Dutta et al., 2006). Thus, this vegetable can contribute to improve nutritional status of the people of Bangladesh, particularly the vulnerable group in respect of vitamin A requirement. Moreover, pumpkin has a long storage

\footnotetext{
${ }^{1}$ Senior Scientific Officer, ${ }^{2}$ Principal Scientific Officer, Postharvest Technology Division, Bangladesh Agricultural Research Institute (BARI), ${ }^{3}$ Senior Scientific Officer, Horticulture Research Centre, BARI, ${ }^{4}$ Senior Scientific Officer, Tuber Crops Research Centre, BARI, Gazipur-1701, Bangladesh.
} 
capacity compared to other vegetables even in ambient temperature and relative humidity. Generally, the growers of Bangladesh store full ripe pumpkin fruits in their house for 3-4 months under ordinary conditions. Yawalkar (1985) reported that well matured pumpkin fruits can be stored for 2-4 months under normal home conditions and therefore, can meet the demand of vegetables supply during slack season. In a preliminary experiment, it was found that the nutritional value of stored pumpkin fruit get deteriorated during storage at higher temperature (30$32{ }^{\circ} \mathrm{C}$ ). During storage, the majority of the physico-chemical changes that occur in the harvested commodities are related with oxidative metabolism, which is highly correlated with change in quality and storage duration (Maiti et al., 2006). Many studies on the postharvest nutrient destruction and textural changes for fruits and vegetables are available, but no study has been made regarding the decline of nutritional quality of pumpkin during storage at ambient conditions. The objective was to study the degradation of $\beta$-carotene and other nutrients of pumpkin during storage under ordinary conditions.

\section{Materials and Method}

Fruits and treatments: Fully matured fruits of BARI pumpkin-1 and BARI pumpkin-2 were harvested from the experimental field of Horticulture Research Centre, BARI, Gazipur on 05 May 2010. Twenty seven pumpkin fruits were selected with uniform size, shape and colour from each variety. The surface of the selected fruits were cleaned with soft cloths and kept in storage up to 120 days under ambient room conditions $\left(27-31{ }^{\circ} \mathrm{C}\right.$ and $75-90 \%$ RH) (Fig.1). Every fortnight, three fruits represented three replications for each variety were used for determining physico-chemical characteristics. A different set of three fruits from each variety was marked to find out the weight loss, and the same set of fruits was used throughout the whole storage period. Data were recorded every fortnight started on the same day of harvest.

Measurements of weight loss: To determine weight loss, individual fruit was weighed with a top pan electronic balance (BP 2100, Sartorius, Germany) at the beginning of the experiment and thereafter each fortnight during the whole storage period. Weight loss was expressed as percentage loss of the initial total weight.

Measurement of $\boldsymbol{\beta}$-carotene: The estimation of $\beta$-carotene was done by the extraction of $3 \mathrm{~g}$ fruit sample with acetone (Fisher Scientific Ltd., UK) and petroleum ether. It was further purified with acetone, methanolic $\mathrm{KOH}$ and distilled water. The resulting solution was filtered with anhydrous sodium sulphate and read on a spectophotometer (T-80, PG Instrument Ltd., UK) at 451 $\mathrm{nm}$ against petroleum ether as a blank. A standard graph was plotted using synthetic crystalline $\beta$-carotene (Fluka, Germany) dissolved in petroleum ether and its optical density measured at $451 \mathrm{~nm}$ (Alasalvar et al., 2005). 


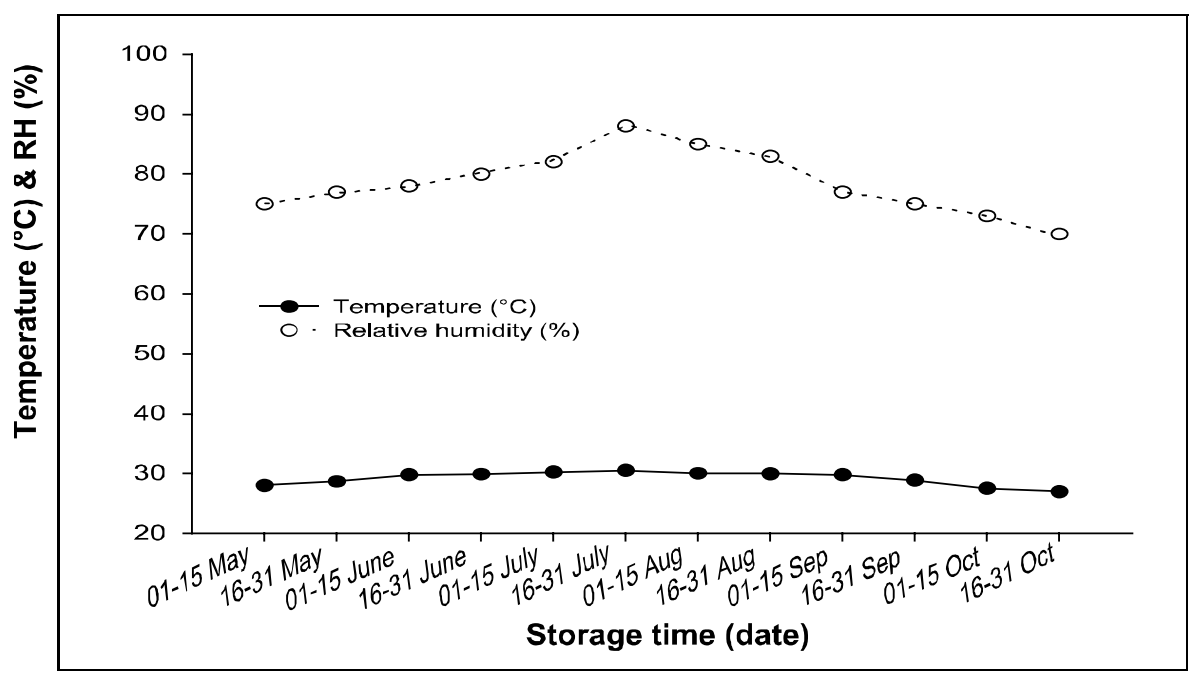

Fig. 1. Changes of temperature and relative humidity of the storage room for pumpkin from May to October 2010.

Measurements of ascorbic acid, total soluble solids (TSS), pH and titratable acidity: Pulp tissues of pumpkin were cut into small pieces. For ascorbic acid measurement, $10 \mathrm{~g}$ pulp tissue was immediately homogenized in $50 \mathrm{~mL}$ of $3 \%$ cold metaphosphoric acid $\left(\mathrm{HPO}_{3}\right)$ using a blender for $2 \mathrm{~min}$ and filtered through Whatman filter paper No. 2. The clear supernatant was collected for assaying ascorbic acid by 2,6-dichlorophenolindophenol titration following the method of Ranganna (1986). Ten milliliters of aliquot was titrated with $0.1 \%$ 2,6-dichlorophenolindophenol solution until the filtrate changed to pink colour persisted for at least 15 seconds and the titration volume of 2,6-dichlorophenolindophenol was recorded. Prior to titration 2,6-dichlorophenolindophenol solution was calibrated by ascorbic acid standard solution. Ascorbic acid content was calculated according to the titration volume of 2,6-dichlorophenolindophenol and results were expressed as mg 100/g fresh weight.

Again, 10 grams of pulp tissues was homogenized in $50 \mathrm{~mL}$ of distilled water for 2 min using a kitchen blender and filtered through Whatman filter paper No. 2. The supernatant was collected in order to measure total soluble solids using a hand refractometer (Model N-1E, Atago, Japan) and expressed as percentage, $\mathrm{pH}$ using a glass electrode $\mathrm{pH}$ meter (Delta 320, Mettler, Shanghai) and titratable acidity expressed as citric acid (\%) was determined by titration with $0.1 \mathrm{~mol} / \mathrm{L}$ $\mathrm{NaOH}$ to $\mathrm{pH} 8.1$ according to the method by Ranganna (1986).

Experimental design and statistical analysis: The experiment was carried out in a completely randomized design (CRD) with three replications. All the analytical works were repeated three times and mean values were used for 

Total soluble solid content: Changes in the TSS content of pumpkin fruits with storage period is presented in Fig. 3. Different storage periods and pumpkin varieties showed significant variation in the changes of TSS content during whole storage period. The initial TSS contents of BARI Pumpkin-1 and BARI Pumpkin-2 were 6.16 and $6.67 \%$, respectively, which gradually increased until 45 days of storage and reached the maximum levels of 8.1 and $8.3 \%$, respectively. After this period, noticeable decrease in TSS content was recorded for both varieties with the values of 6.6 and $6.8 \%$ for BARI Pumpkin- 1 and BARI Pumpkin-2, respectively by the end of storage. These findings are in agreement with Maiti et al. (2006), who reported that the general tendency of TSS in climacteric fruits and vegetables is to increase with an initial increase in sugar followed by a decrease.

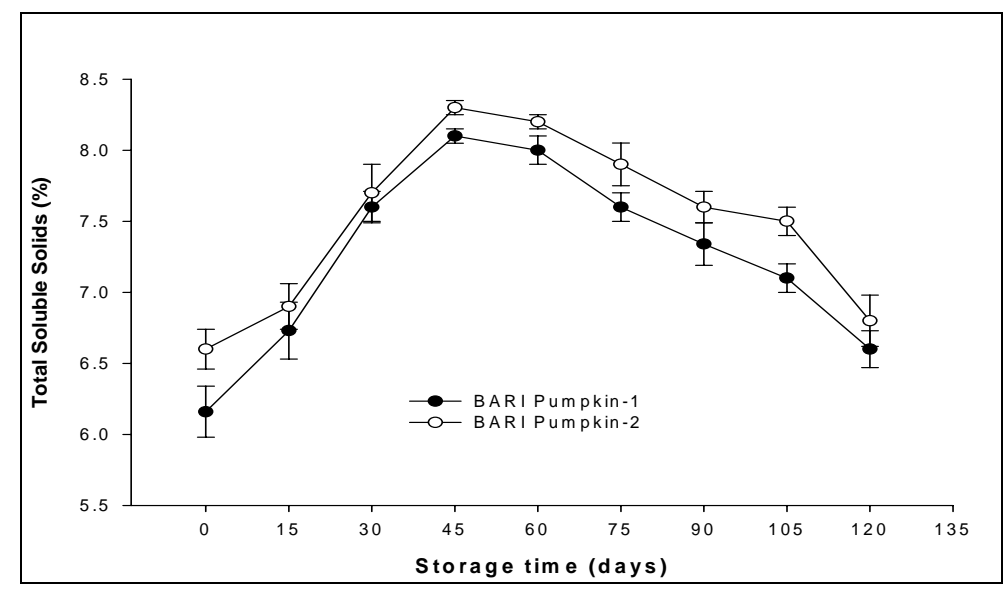

Fig. 3. Effect of variety and storage time on the changes in total soluble solids contents of pumpkins stored for 120 days under ambient conditions $\left(27-31^{\circ} \mathrm{C}\right.$ and $75-90 \%$ $\mathrm{RH})$. Vertical bar represents standard deviation.

$\beta$-carotene content: $\beta$-carotene degradation of pumpkin fruits which were stored under ambient conditions over a period of 120 days was investigated. It is evident from Fig. 4 that storage duration of pumpkin fruits led to a significant decrease in $\beta$-carotene content of both the varieties. The initial $\beta$-carotene contents were 36.5 $\mu \mathrm{g} / \mathrm{g}$ and $37.3 \mu \mathrm{g} / \mathrm{g}$ for BARI Pumpkin-1 and BARI Pumpkin-2, respectively, which were drastically reduced to $16.5 \mu \mathrm{g} / \mathrm{g}$ and $17.16 \mu \mathrm{g} / \mathrm{g}$, respectively, after 30 days of storage. These decreases might be possible due to the higher temperature and $\mathrm{RH}(\%)$ existed in the storage room. In general, oxidation is a major cause of $\beta$-carotene destruction (Simpson, 1985). Dutta et al. (2006) reported that the thermal degradation of pumpkin tissue caused in the loss of $\beta$ carotene content. Thermal processing also results in losses of trans- $\beta$-carotene and formation of cis isomers as reported by many authors (Chen and Chen, 1994; 
Khachik et al., 1992; Chandler and Schwartz, 1988). After 30 days of storage, pumpkin fruits showed a gradual decline in $\beta$-carotene content and exhibited the minimum values of $5.4 \mu \mathrm{g} / \mathrm{g}$ and $5.63 \mu \mathrm{g} / \mathrm{g}$ for BARI Pumpkin-1 and BARI Pumpkin-2, respectively, at the end of storage period.

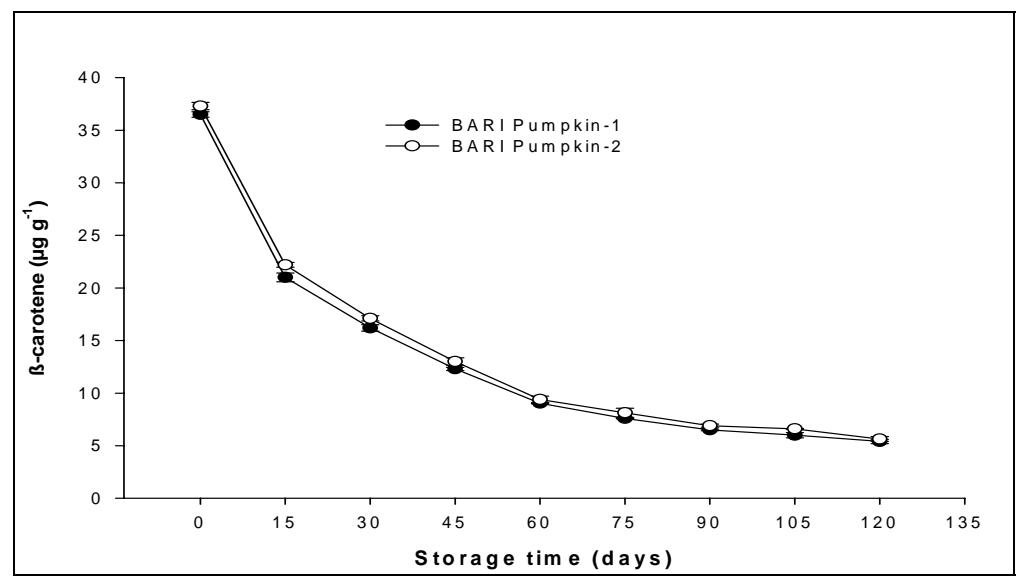

Fig. 4. Effect of variety and storage time on the changes in $\beta$-carotene contents of pumpkins stored for 120 days under ambient conditions $\left(27-31^{\circ} \mathrm{C}\right.$ and $75-90 \%$ $\mathrm{RH})$. Vertical bar represents standard deviation.

Ascorbic acid, titratable acidity and pH: Different storage periods induced significant variation in ascorbic acid content of both pumpkin varieties during storage (Fig. 5). Initially, the ascorbic acid contents of BARI Pumpkin-1 and BARI Pumpkin-2 were recorded by 11.2 and $9.31 \mathrm{mg} / 100 \mathrm{~g}$, respectively. The contents were gradually declined over the storage period and reached the minimum levels of 5.2 and $4.91 \mathrm{mg} / 100 \mathrm{~g}$ for BARI Pumpkin-1 and BARI Pumpkin-2, respectively, by the end of storage. Both the varieties and different storage time showed significant differences in ascorbic acid contents during whole storage period.

Titratable acidity (TA) and $\mathrm{pH}$ of pumpkins were also significantly affected by storage durations. At the beginning of storage (day ' 0 '), the TA of pumpkins was higher with the values of 0.17 and $0.15 \%$ for BARI Pumpkin- 1 and BARI Pumpkin-2, respectively (Fig. 6). As storage progressed TA was slowly declined and reached the minimum levels of $0.11 \%$ for both varieties by the end of storage.

The changes in $\mathrm{pH}$ of pumpkins as function of varieties and different storage periods are shown in Fig. 7. The initial $\mathrm{pH}$ values were 6.49 and 6.47 for BARI Pumpkin-1 and BARI Pumpkin-2, respectively, which gradually increased during storage with significant differences $(\mathrm{P} \leq 0.05)$ between varieties and storage 
periods. At the end of storage, $\mathrm{pH}$ values reached the maximum levels of 6.85 and 6.80 for BARI Pumpkin-1 and BARI Pumpkin-2, respectively.

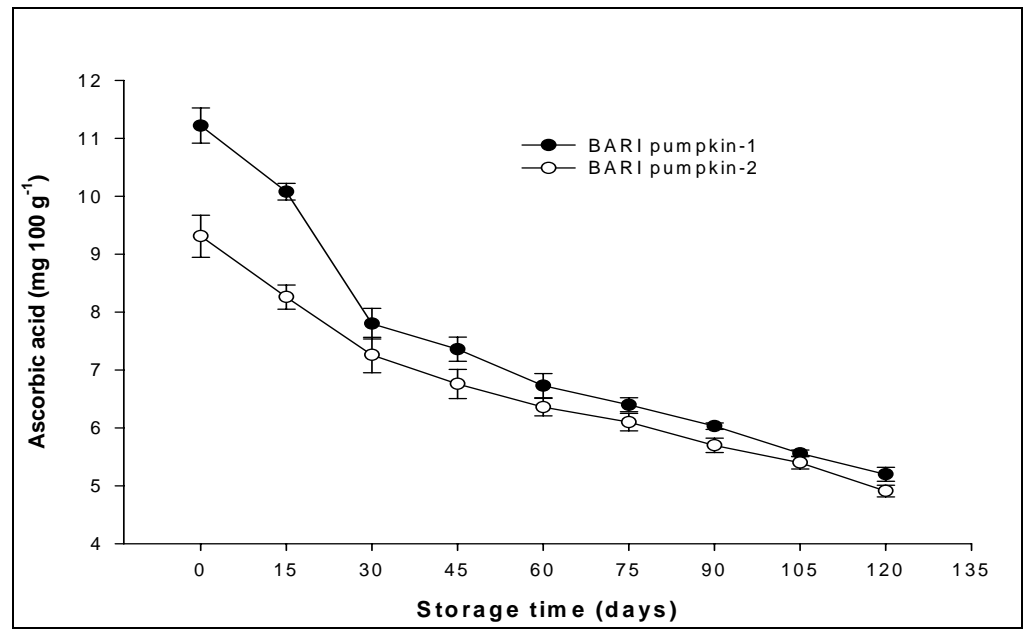

Fig. 5. Effect of variety and storage time on the changes in ascorbic acid contents of pumpkins stored for 120 days under ambient conditions $\left(27-31^{\circ} \mathrm{C}\right.$ and $75-90 \%$ $\mathrm{RH})$. Vertical bar represents standard deviation.

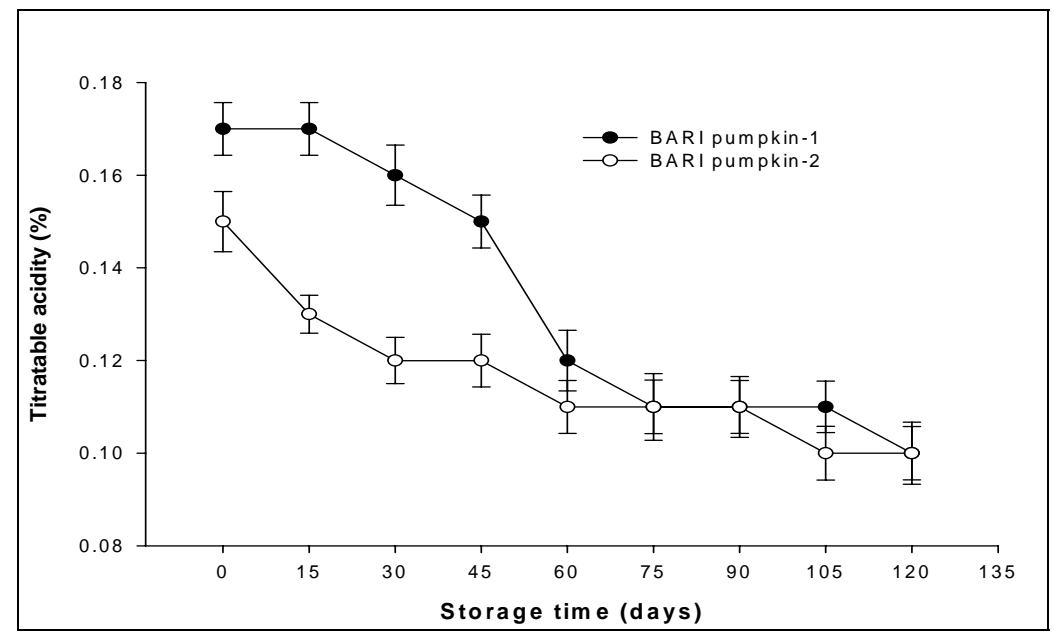

Fig. 6. Effect of variety and storage time on the changes in titratable acidity of pumpkins stored for 120 days under ambient conditions $\left(27-31^{\circ} \mathrm{C}\right.$ and $\left.75-90 \% \mathrm{RH}\right)$. Vertical bar represents standard deviation.

The changes in ascorbic acid contents and titratable acidity during storage vary depending on the crop maturity and storage temperature (Maiti et al., 2006). 
The recommended storage temperature and $\mathrm{RH}$ of pumpkin are $12.2^{\circ} \mathrm{C}$ and 70 $75 \%$, respectively, for 84-160 days (SeaLand, 1991). In another experiment, Snowdon (1991) found that the best temperature and RH for pumpkin were 10-13 ${ }^{\circ} \mathrm{C}$ and $60-70 \%$, respectively, for $2-5$ months of storage. In the present study, pumpkin fruits were stored at $27-31{ }^{\circ} \mathrm{C}$ and $75-90 \% \mathrm{RH}$ (ambient room conditions), which were much higher than that of recommended storage conditions. The higher temperature and RH prevailed in the storage room might be the major causes for rapid declining of ascorbic acid and TA content. The results are in agreement with Maiti et al. (2006) who reported that the ascorbic acid contents decrease rapidly at higher storage temperature. As acidity of the fruits decreased, simultaneously the $\mathrm{pH}$ values increased over the storage period.

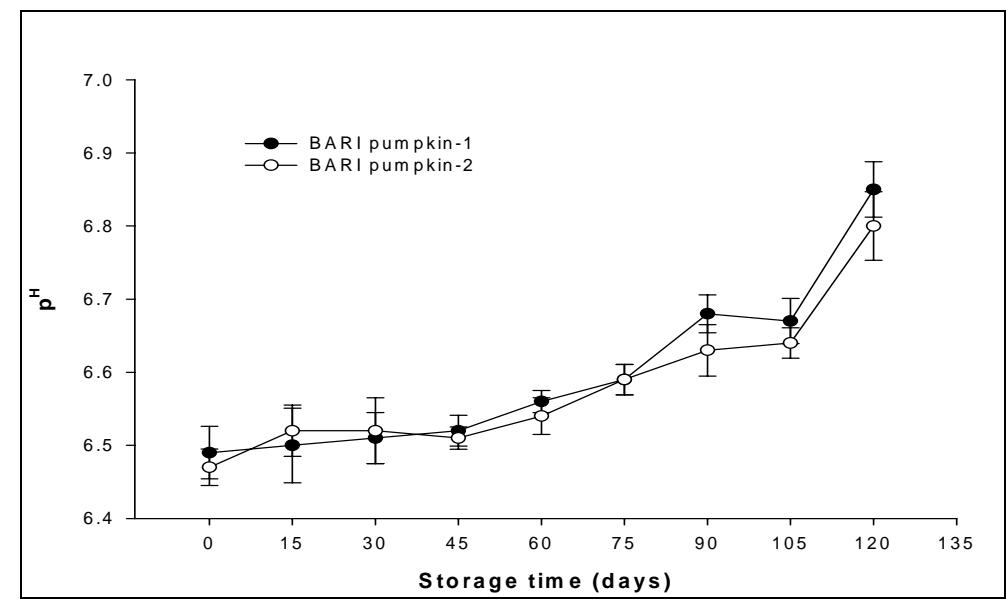

Fig. 7. Effect of variety and storage time on the changes in $\mathrm{pH}$ of pumpkins stored for 120 days under ambient conditions $\left(27-31^{\circ} \mathrm{C}\right.$ and $\left.75-90 \% \mathrm{RH}\right)$. Vertical bar represents standard deviation.

Results of the present study showed that long term storage of pumpkin at ambient room temperature and $\mathrm{RH}$ led to a considerable degradation of nutritional values of pumpkin particularly in $\beta$-carotene, ascorbic acid, and TSS contents. Both storage duration and pumpkin varieties had significant effect on the degradation of these nutritional elements. The rate of degradation of $\beta$ carotene and ascorbic acid was much higher during first 30 days of storage. Further studies are required to optimize the storage conditions of pumpkins for maintaining better fruit quality during storage.

\section{References}

Alasalvar, J. E., M. Al-Farsi, P.C. Quantic, F. Shahidi, and R.Wiktorowicz. 2005. Effect of chill storage and modified atmosphere packaging (MAP) on antioxidant, phenolics 
and sensory quality of ready-to-eat shredded orange and purple carrots. Food Chem. 89: 69-76.

Bose, T.K. and M.G. Som. 1986. Vegetable Crops in India. Naya Prokash, Calcutta. Pp. 92-95.

Boxall, R.A., J.R. Brice, S.J. Taylor, and R.D. Bancroft. 2002. Technology and management of storage. In: Crop Post-Harvest: Science and Technology-Principles and Practice, Vol. 1. Golob, P., Farrell, G. and Orchard, J.E. (eds). Blackwell Publishing, Pp. 141-232.

Burdon, J.N. 1997. Postharvest handling of tropical and subtropical fruits for export. In: Postharvest Physiology and Storage of Tropical and Subtropical Fruits. Mitra, S. (Ed), CAB International, UK. pp. 01-19.

Chandler, L.A. and S.J. Schwartz. 1988. Isomerization and losses of trans $\beta$-carotene in sweet potatoes as affected by processing treatment. J. Agric. Food Chem. 36: 129133.

Chen, T.M. and B.H. Chen. 1994. Optimization of mobile phase for the HPLC of cistrans carotene isomers. Chromatographia 39: 346-354.

Dutta, D., U.R. Chaudhuri, and R. Chakraborty. 2006. Effect of thermal treatment on the $\beta$-carotene content, colour and textural properties of pumpkin. J. Food Sci. Technol. 43 (6): 607-611.

Kahchik, F., M. Goli, G. Beecher, J. Holden, W. Lusdy, M. Tenorio, and M. Barreia. 1992. Effect of food preparation on qualitative and quantitative distribution of major carotenoid constituents of tomatoes and several green vegetables. J. Agric. Food Chem. 40: 390-398.

Kumar, A., B.S. Ghuman, and A.K. Gupta. 1999. Non-refrigerated storage of tomatoeseffect of HDPE film rapping. J. Food Sci. Technol. 36: 438-440.

Maiti, R.K., N.C. Sarkar, and V.P. Singh. 2006. Principles of Post harvest Seed Physiology and Technology. Agrobios, India. p. 450.

SeaLand. 1991. Shipping guide to perishables. SeaLand Service Inc., PO Box 800, Iselim, New Jersey 08830, USA.

Simpson, K.L. 1985. Chemical changes in natural food pigments. In: Chemical changes in food during processing. Richardson, T. and J.W. Finley (eds), AVI. Westport, CT, Pp. 409-441.

Snowdon, A.L. 1991. A Colour Atlas of Postharvest Diseases and Disorders of Fruits and Vegetables. Vol. 2. Wolfe Scientific Ltd., London, P. 416.

Ranganna, S., 1986. Handbook of Analysis and Quality Control for Fruit and Vegetable Products, $2^{\text {nd }}$ Edition. Tata McGraw-Hill, New Delhi, India, P. 1112.

Thompson, A.K. 1996. Postharvest Technology of Fruits and Vegetables. Blackwell Science Ltd. P. 410

Yawallkar, K.S. 1985. Vegetable Crops in India, $3^{\text {rd }}$ Edition, Agric. Hort. Pub. House, Nagpur-440010. Pp. 158-162. 